\title{
Otimização do uso dos recursos hídricos na irrigação: estudo de caso no Açude Aracagi-Paraíba
}

A agricultura irrigada consome cada dia mais água devido ao seu crescente uso para produção de alimentos. Os recursos hídricos estão disponíveis de forma irregular, variando de região para região. Essa característica se torna mais visível na região semiárida nordestina, onde a pluviosidade é baixa e irregular, dificultando o desenvolvimento agrícola. Dessa maneira, fica impraticável o uso da água de forma contínua e indefinida, sem um planejamento estratégico para a preservação da disponibilidade e qualidade hídrica. É possível estabelecer estratégias para uso adequado deste recurso na agricultura irrigada, avaliando a possibilidade de ferramentas que possam contribuir para o direcionamento de uma agricultura planejada otimizando os recursos naturais. Dentro deste contexto, este trabalho tem como objetivo otimizar o uso da água por meio da eficiência da aplicação desta na irrigação, proporcionando ganhos de produtividade sem comprometimento da disponibilidade deste recurso. O trabalho traz a avaliação do uso da água de um outorgado do reservatório de Araçagi, estado da Paraíba, Brasil, realizado em um ambiente EXCEL. A metodologia aplicada foi a Programação Linear na Otimização e os resultados obtidos mostram que a água disponibilizada é maior do que o consumo do produtor, sendo desta forma possível ampliar sua produção com esta disponibilidade hídrica ou minimizar a quantidade de água disponibilizada. Ainda é possível aferir que a água outorgada pode ser utilizada de forma mais eficiente, como também, o processo de disponibilização de outorga hídrica pode ser melhor avaliado pelo outorgante, visando uma segurança hídrica futura.

Palavras-chave: Agricultura Irrigada; Recursos Hídricos; Otimização; Segurança Hídrica.

\section{Optimization of the use of water resources in irrigation: a case study in Araçagi Dike-State Of Paraíba}

\begin{abstract}
Irrigated agriculture consumes more water each day due to its increase use for food production. Water resources are available irregularly, varying from region to region. This feature becomes more visible in the northeastern semi-arid region, where rainfall is low and irregular, making agricultural development difficult. In this way, it is impracticable to use the water in a continuous and indefinite way, without a strategic planning for the preservation of water availability and quality. It is possible to establish strategies for the adequate use of this resource in irrigated agriculture, evaluating the possibility of tools that can contribute to the direction of a planned agriculture optimizing the natural resources. In this context, the objective of this work is to optimize the use of water through the efficiency of its application in irrigation, providing productivity gains without compromising the availability of this resource. The paper intents the evaluation of the water use from a given Araçagi Dike, state of Paraíba, Brazil, accomplished in the EXCEL software. The methodology applied was the Linear Programming in Optimization and the results obtained show that the water available is bigger than the consumption of the producer, and this way it is possible to increase its production with this water availability or to minimize the amount of water available. It is still possible to verify that the water granted can be used in a more efficient way, as well as, the process of making water granting available can be better evaluated by the grantor, looking at a future water security.
\end{abstract}

Keywords: Irrigated Agriculture; Water Resources; Optimization; Water Security.

Topic: Engenharia de Recursos Hídricos

Reviewed anonymously in the process of blind peer
Received: 10/08/2018

Approved: 24/09/2018
Virgínia da Costa Brito (D)

Universidade Federal de Campina Grande, Brasil

http://lattes.cnpq.br/3293234957426500

http://orcid.org/0000-0002-5776-0612

virginia.dcb@gmail.com

Cícero Fellipe Diniz de Santana (iD)

Universidade Federal de Campina Grande, Brasil

http://lattes.cnpq.br/7916729062952119

http://orcid.org/0000-0002-9228-3903

cicero.esa@hotmail.com

Luísa Eduarda Lucena de Medeiros (ii

Universidade Federal de Campina Grande, Brasi

http://lattes.cnpq.br/7932530323230086

http://orcid.org/0000-0002-9792-1273

lu.mdeiros@gmail.com

\author{
Valterlin da Silva Santos \\ Universidade Federal de Campina Grande, Brasil \\ http://lattes.cnpq.br/4740303724015282 \\ http://orcid.org/0000-0002-4789-2937 \\ valterlin@yahoo.com.br \\ Wilson Fadlo Curi (iti) \\ Universidade Federal de Campina Grande, Brasil \\ http://lattes.cnpq.br/4941338019932170 \\ http://orcid.org/0000-0002-7024-7127 \\ wfcuri@yahoo.com.br
}

Referencing this:

BRITO, V. C.; SANTANA, C. F. D.; MEDEIROS, L. E. L.; SANTOS, V. S.; CURI, W. F.. Otimização do uso dos recursos hídricos na irrigação: estudo de caso no Açude Aracagi-Paraíba. Revista Ibero Americana de Ciências Ambientais, v.9, n.7, p.52-61, 2018. DOI:

http://doi.org/10.6008/CBPC2179-6858.2018.007.0006

DOI: 10.6008/CBPC2179-6858.2018.007.0006 


\section{INTRODUÇÃO}

A quantidade de água existente na natureza é finita e sua disponibilidade vem diminuindo com o crescente aumento populacional que acarreta na expansão das fronteiras agrícolas, a qual é responsável por boa parte do consumo de água no mundo. Tundise et al. (2011), afirmam que:

Através dos séculos, a complexidade dos usos múltiplos da água pelo homem aumentou e produziu um enorme volume de degradação e poluição. Por outro lado, os usos múltiplos excessivos e as retiradas permanentes para diversas finalidades têm diminuído consideravelmente a disponibilidade de água e produzido inúmeros problemas de escassez em muitas regiões e países.

Em regiões semiáridas, caracterizadas pela baixa precipitação em épocas do ano, é de fundamental importância o manejo de água para os diversos usos. O uso da água na irrigação deve atender à necessidade hídrica das culturas de forma mais eficiente evitando excessos ou escassez desse recurso. O manejo adequado corresponde na aplicação da quantidade correta de água em cada tipo de cultura, para isso, fazse necessário um planejamento, levando-se em consideração todo o processo de produção das culturas com suas especificidades, evitando o desperdício de água, o estresse hídrico da cultura, o qual pode comprometer a produção. Quanto ao manejo adequado do uso da água na agricultura irrigada, os métodos de irrigação podem ser aprimorados e avaliados de acordo com as necessidades hídricas de cada cultura, e assim, minimizar os impactos negativos decorrentes da falta de planejamento, como o carreamento de sedimentos, defensivos agrícolas, fertilizantes, resultando na minimização da degradação dos recursos hídricos. Segundo Resende Filho (2011), é necessária a utilização de práticas adequadas e eficientes do uso da água, para que esta atividade se torne sustentável.

Câmara Junior (2005) afirma que a utilização de modelos matemáticos é uma ferramenta imprescindível na busca destes objetivos, pois permite ao usuário atingir resultados ótimos e prever possíveis falhas durante sua execução. Diante do exposto, este trabalho tem como objetivo avaliar a eficiência do uso da água para irrigação de um produtor rural do reservatório de Araçagi-PB, por meio da análise de Programação Linear (PL), utilizando a metodologia SIMPLEX para maximizar o lucro, minimizando o consumo de água para as culturas, proporcionando ao produtor um aumento em suas receitas líquidas além da preservação e conservação dos recursos naturais.

\section{REVISÃO TEÓRICA}

Sobre irrigação de acordo com a ANA (2017):

Atualmente, o principal uso de água no país, em termos de quantidade utilizada, é a irrigação. Esse uso corresponde à prática agrícola que utiliza um conjunto de equipamentos e técnicas para suprir a deficiência total ou parcial de água para as culturas, e varia de acordo com a necessidade de cada cultura, tipo de solo, relevo, clima e outras variáveis. Normalmente, a irrigação permite uma suplementação do regime de chuvas, viabilizando o cultivo em regiões com escassez mais acentuada de água, como o Semiárido, ou em locais com períodos específicos de seca, como a região central do Brasil.

Segundo Vieites (2010), com o advento da modernização da agricultura operada no século XX, por causa dos métodos adotados, houve uma intensificação da destruição da natureza pelos processos agropecuários e estes processos maximizaram a produção agropecuária, representando um agravamento 
dos problemas ambientais, bem como os socioeconômicos. Sendo a água um recurso indispensável a sobrevivência dos seres vivos, é de fundamental importância o debate sobre as relações entre homem e água, uma vez que esta relação hoje é prejudicial ao meio ambiente, necessitando de uma mudança neste quadro para assegurar a sobrevivência das gerações futuras.

De acordo com Farias (2004), na Matemática existem dois tipos de modelos básicos, utilizados para estudar sistemas de recursos hídricos, são os modelos de otimização e de simulação. A finalidade do modelo de otimização é maximizar ou minimizar uma determinada função objetivo, enquanto que o modelo de simulação, sendo mais flexível o seu algoritmo, permite analisar o sistema de acordo com cenários de operação propostos.

Curi et al. (2002) afirmam que um planejamento eficiente na agricultura irrigada proporciona um aumento na produtividade e na geração de emprego e renda, promovendo, assim, uma vida melhor para os agricultores, como no caso do semiárido paraibano onde se faz uso de açudes e poços para abastecimento, sendo assim, a aplicação da otimização traz informações importantes aos produtores para que consigam produzir mais utilizando menos água, realizando assim, uma atividade eficiente.

Segundo Lanna (1997), são dois os grandes propósitos da análise de sistemas de recursos hídricos: simular o comportamento da realidade que eles representam e otimizar os processos decisórios que atuam sobre a realidade, o que dá origem à margem de utilização de duas técnicas mais usuais, que são de simulação e otimização. A técnica da Programação Linear é uma das mais aplicadas na busca de tomadas de decisão em planejamento de recursos hídricos. Neste tipo de programação as restrições do sistema são representadas por expressões também lineares que buscam a solução ótima da função objetivo do problema, também linear.

A otimização de um dado problema busca atender aos objetivos que são estabelecidos pelo sistema. A partir das restrições impostas ao sistema, pode-se chegar a solução ótima da função objetivo. Os modelos de otimização maximizam ou minimizam a função objetivo de acordo com o problema apresentado. Com as ferramentas computacionais disponíveis atualmente, encontram-se algumas destas ferramentas que podem ser manipulados para a resolução de problemas de Programação Linear, como por exemplo, LINUS, MATLAB, EXCEL, entre outras.

\section{MATERIAIS E MÉTODOS}

\section{Área de Estudo}

A bacia hidrográfica do Rio Mamanguape (Figura 1) está situada no extremo leste da Paraíba, com regime intermitente, área de drenagem de aproximadamente $3.525,00 \mathrm{~km}^{2}$, sendo a segunda maior bacia do leste do Estado da Paraíba, localizada entre as latitudes 6o 36' 49" - 70 11' 08" S e longitudes 340 54' 42" 350 57' 51" O, inserida nas mesorregiões da Zona da Mata e Agreste paraibano (PERH, 2006). 


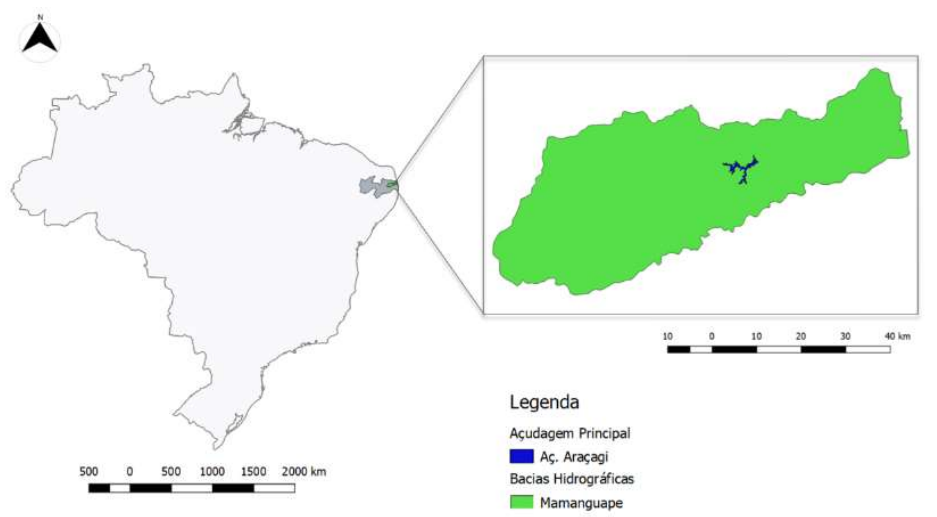

Figura 1: Localização da Bacia do Rio Mamanguape e do Açude Araçagi.

O açude Araçagi está localizado na bacia no Rio Mamanguape, sendo um dos principais reservatórios de acumulação da bacia, com uso de água para irrigação, abastecimento humano e dessedentação animal e as seguintes características hidrológicas constadas na Tabela 1.

Tabela 1: Características hidrológicas do açude Araçagi.

\begin{tabular}{|l|l|}
\hline Bacia Hidrográfica & Mamanguape \\
\hline Capacidade Total & $63.289 .037,00 \mathrm{~m}^{3}$ \\
\hline Localização & Araçagi - PB \\
\hline Rio Barrado & Mamanguape \\
\hline Área da Bacia Hidrográfica & $3.525,00 \mathrm{~km}^{2}$ \\
\hline Volume Morto & $2.517 .437 \mathrm{~m}^{3}$ \\
\hline Área do Açude & $1.310 \mathrm{~km}^{2}$ \\
\hline Vazão de Regularização & $2.225,75 \mathrm{I} / \mathrm{s}$ \\
\hline Posto pluviométrico representativo & Araçagi (3839727) \\
\hline
\end{tabular}

Fonte: PERH (2006).

\section{Otimização - Método SIMPLEX}

A técnica da PL é uma das mais aplicadas na busca de tomadas de decisão em planejamento de recursos hídricos. Neste tipo de programação as restrições do sistema são representadas por expressões também lineares que buscam a solução ótima da função objetivo do problema, também linear. A otimização de um dado problema busca atender aos objetivos que são estabelecidos pelo sistema. A partir das restrições impostas ao sistema, pode-se chegar a solução ótima da função objetivo (FO). Os modelos de otimização maximizam ou minimizam a FO de acordo com o problema apresentado.

No entanto, não existe um procedimento geral de otimização que possa resolver eficientemente qualquer tipo de problema. A maioria das técnicas depende da forma e das propriedades matemáticas da função-objetivo e das restrições (MATEUS et al., 1986). O fluxograma descrito na Figura 2 ilustra como foi estruturado o processo de simulação e otimização do problema em estudo.

As variáveis que foram utilizadas para a execução do processo de otimização foram: receita por cultura, outorga por cultura e consumo do plantio, conforme ilustrado na Figura 2. A partir destas, foi possível estruturar a FO com suas respectivas restrições. O objetivo da função foi maximizar o lucro do produtor, minimizando o consumo de água na área em estudo, devendo a solução encontrada pelo modelo atender a todas as restrições deste. Caso contrário, escolhe-se novas variáveis de base com suas variáveis de folga e executa-se o modelo novamente. 


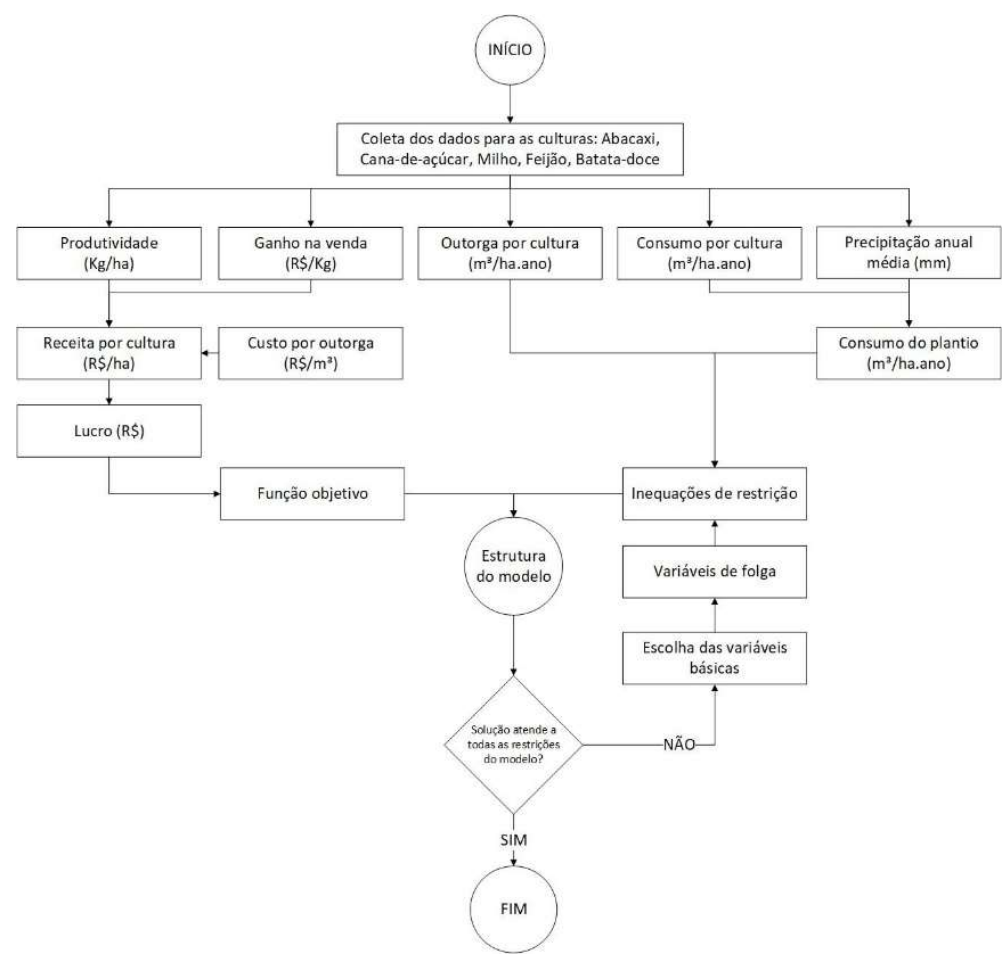

Figura 2: Fluxograma das etapas de construção do modelo de otimização.

Um modelo de PL sempre será formado por equações lineares e para Ragsdale (2009), é possível expressar todas as funções de um modelo de PL como uma soma ponderada, ou combinação linear das variáveis de decisão. Assim, um modelo de PL possui uma FO, e as demais são inequações que representam as restrições:

$$
\begin{gathered}
\text { MAX. (ou MIN): c1X1 +c2X2 +... cnXn } \\
\text { Sujeito a: } a 11 X 1+a 12 X 2+\ldots+a 1 n X n \leq b 1 \\
\text { aknX1 + ak2X2 }+\ldots+a k n X n \geq b k \\
\text { am1X1 }+a m 2 X 2+\ldots+a m n X n=b m
\end{gathered}
$$

Inicialmente, o modelo apresentou uma solução básica inicial. As restrições do problema em estudo apresentaram apenas relação do tipo $\leq$, caracterizando a não negatividade, com variáveis de folga incluídas nas equações de balanceamento para as restrições.

\section{Variáveis de entrada}

Para realização deste trabalho, foi escolhido um usuário de água de uma propriedade localizada em Araçagi-PB que utiliza a água do manancial do município para agricultura, com irrigação de cinco culturas: cana-de-açúcar, feijão, milho, batata doce e abacaxi em uma área total de quatro hectares cultiváveis para todo o plantio.

Também foram coletados os dados de outorga concedida para a propriedade, conforme cada cultura irrigada, sendo o volume de água utilizada anualmente fornecido pela AESA (Agência Executiva de Águas da Paraíba). Para a obtenção dos gastos com a cobrança pelo uso deste recurso, foi utilizada a taxa de 0,005 reais por metro cúbico de água disponibilizado, valor conferido pela AESA para irrigação no estado da Paraíba. 
O valor da venda dos produtos contabilizada em reais por quilo produzido, foram obtidos através de dados dos relatórios e monitoramentos da EMPASA (Empresa Paraibana de Abastecimento e Serviços Agrícolas) e da CONAB (Companhia Nacional de Abastecimento), bem como valores de produtividade das culturas medidos em kg/ha, encontrados para região Nordeste, mais precisamente para o estado da Paraíba.

A quantidade de água requerida por cada cultura, foi obtida através de boletins e documentos da EMBRAPA (Empresa Brasileira de Pesquisa Agropecuária), que fornecem dados de precipitação anual mínima necessária para o desenvolvimento das culturas. Através da EMBRAPA também foram coletadas informações sobre o número de safras de cultura em estudo. Conjuntamente com os dados de precipitação requeridas para as culturas, foi obtido o valor da precipitação média anual da região pela AESA, para que seja subtraída da quantidade de água irrigada necessária para o cultivo. A Tabela 2 apresenta todos os valores requeridos para a elaboração das variáveis de entrada.

Tabela 2: Dados das culturas irrigadas.

\begin{tabular}{|c|c|c|c|c|c|c|c|c|}
\hline Cultura & $\begin{array}{l}\text { Ciclos } \\
\text { de safra }\end{array}$ & $\begin{array}{l}\text { Área } \\
\text { Plantada } \\
\text { (ha) } \\
\end{array}$ & $\begin{array}{l}\text { Outorga } \\
\text { (m³/ano) }\end{array}$ & $\begin{array}{l}\text { Custo da } \\
\text { outorga } \\
\text { (R\$) }\end{array}$ & $\begin{array}{l}\text { Produção } \\
\text { (kg/ha) }\end{array}$ & $\begin{array}{l}\text { Ganho na } \\
\text { venda } \\
(\mathrm{R} \$ / \mathrm{kg})\end{array}$ & $\begin{array}{l}\text { Precipitação } \\
\text { para plantio } \\
(\mathrm{mm})\end{array}$ & $\begin{array}{l}\text { Precipitação } \\
\text { média anual } \\
(\mathrm{mm})\end{array}$ \\
\hline Milho & 3 & 0,4 & 20.592 & 102,96 & 463 & 0,90 & 640 & $1.007,33$ \\
\hline Abacaxi & 1 & 2,0 & 20.592 & 102,96 & $45.049,5$ & 1,5 & 2.000 & $1.007,33$ \\
\hline Feijão & 3 & 0,2 & 20.592 & 102,96 & 270 & 3,16 & 500 & $1.007,33$ \\
\hline $\begin{array}{l}\text { Cana-de- } \\
\text { açúcar }\end{array}$ & 1 & 0,4 & 20.592 & 102,96 & 44.014 & 0,7 & 1.500 & $1.007,33$ \\
\hline $\begin{array}{l}\text { Batata } \\
\text { doce }\end{array}$ & 3 & 1,0 & 20.592 & 102,96 & 8.322 & 0,167 & 750 & $1.007,33$ \\
\hline Total & - & 4,0 & 102.960 & 514,8 & $98.118,5$ & 7,427 & - & - \\
\hline
\end{tabular}

Os valores encontrados para produtividade e ganho na venda da produção, quando multiplicados, resultam nos valores da receita obtida pelo plantio. Subtraída a quantia referente aos gastos de custo por outorga, é quantificado o lucro anual por meio da produção das culturas. O consumo de água foi calculado a partir dos valores das precipitações necessárias para o plantio, da área da propriedade e dos ciclos de safras de cada cultura. Junto com esses valores, deve ser considerada a precipitação média anual da região, que contribui para a diminuição do volume de água requerido do reservatório para irrigação.

A variável que representa um fator limitante para a produção agrícola é o volume de água outorgado. A quantidade de água disponibilizada pela outorga está associada as restrições do modelo, sendo estabelecido que quando o consumo atingir o volume de água da outorga, este deve ser interrompido. De posse das variáveis lucro, consumo e outorga, foi possível estruturar o problema. A Tabela 3 apresenta os dados das culturas que são cultivadas pelo produtor a serem utilizados no modelo de otimização.

Tabela 3: Dados das culturas cultivadas pelo produtor.

\begin{tabular}{|l|l|l|l|l|l|l|}
\hline \multirow{2}{*}{ Variáveis } & Cultura & \multicolumn{2}{l|}{} \\
\cline { 2 - 7 } & Milho & Abacaxi & Feijão & Cana-de-açúcar & Batata doce & Total \\
\hline Lucro na área $(\mathrm{R} \$ / \mathrm{ha})$ & 313,74 & $67.471,3$ & 750,24 & $30.706,8$ & $9.608,82$ & $108.850,9$ \\
\hline Consumo na área $\left(\mathrm{m}^{3} / \mathrm{ha}\right)$ & $9.126,7$ & $9.926,7$ & $4.926,7$ & $4.926,7$ & $12.426,7$ & $41.333,5$ \\
\hline Outorgado na área $\left(\mathrm{m}^{3} /\right.$ ha.ano) & 20.592 & 20.592 & 20.592 & 20.592 & 20.592 & 102.960 \\
\hline
\end{tabular}

Fonte: AESA (2017). 
De acordo com a Tabela 2, é possível perceber que as culturas que possuem maior plantio das áreas cultivadas são o abacaxi e a batata doce, respectivamente. A necessidade hídrica para cada cultura foi coletada a partir de dados disponibilizados pela EMBRAPA, para o ano de 2013 referente às cinco culturas plantadas na área de estudo. O modelo de programação linear do problema está descrito abaixo nas equações de função objetivo com suas respectivas restrições, onde as variáveis de decisão são caracterizadas como x1, x2, x3, x4 e x5, as quais representam respectivamente as culturas de milho, abacaxi, feijão, canade-açúcar e batata doce.

$$
\begin{gathered}
\text { Máx. } Z=313,74 x_{1}+67471,29 x_{2}+750,24 x_{3}+30706,84 x_{4}+9608,82 x_{5} \\
x_{1}+x_{2}+x_{3}+x_{4}+x_{5}=4 \\
9126,7 x_{1}+9926,7 x_{2}+4926,7 x_{3}+4926,7 x_{4}+12426,7 x_{5}+x F 1 \leq 102960 \\
9126,7 x_{1}+x_{2}+x_{3}+x_{4}+x_{5}+x F 2 \leq 20592 \\
x_{1}+9926,7 x_{2}+x_{3}+x_{4}+x_{5}+x F 3 \leq 20592 \\
x_{1}+x_{2}+4926,7 x_{3}+x_{4}+x_{5}+x F 4 \leq 20592 \\
x_{1}+x_{2}+x_{3}+4926,7 x_{4}+x_{5}+x F 5 \leq 20592 \\
x_{1}+x_{2}+x_{3}+x_{4}+12426,7 x_{5}+x F 6 \leq 2059
\end{gathered}
$$

Os valores de $x F 1, x F 2, x F 3, x F 4, x F 5$ e $x F 6$ descrevem respectivamente as variáveis de folga para a outorga total e outorgas das culturas de milho, abacaxi, feijão, cana-de-açúcar e batata doce. A Tabela 4 representa a estruturação das equações acima demonstradas em ambiente EXCEL.

Tabela 4: Estruturação do problema de acordo com o SIMPLEX.

\begin{tabular}{|l|l|l|l|l|l|l|l|l|l|l|l|l|l|}
\hline $\mathbf{Z}$ & $\mathbf{x 1}$ & $\mathbf{x}$ & $\mathbf{x 3}$ & $\mathbf{x 4}$ & $\mathbf{x 5}$ & $\mathbf{a 1}$ & $\mathbf{x F 1}$ & $\mathbf{x F 2}$ & $\mathbf{x F 3}$ & $\mathbf{x F 4}$ & $\mathbf{x F 5}$ & $\mathbf{x F 6}$ & $\mathbf{b}$ \\
\hline 1 & $-313,74$ & $-67471,3$ & $-750,24$ & -30707 & $-9608,8$ & $\mathrm{M} 1$ & 0 & 0 & 0 & 0 & 0 & 0 & 0 \\
\hline 0 & 1 & 1 & 1 & 1 & 1 & 1 & 0 & 0 & 0 & 0 & 0 & 0 & 4 \\
\hline 0 & 9126,7 & 9926,7 & 4926,7 & 4926,7 & 12426,7 & 0 & 1 & 0 & 0 & 0 & 0 & 0 & 102960 \\
\hline 0 & 9126,7 & 0 & 0 & 0 & 0 & 0 & 0 & 1 & 0 & 0 & 0 & 0 & 20592 \\
\hline 0 & 0 & 9926,7 & 0 & 0 & 0 & 0 & 0 & 0 & 1 & 0 & 0 & 0 & 20592 \\
\hline 0 & 0 & 0 & 4926,7 & 0 & 0 & 0 & 0 & 0 & 0 & 1 & 0 & 0 & 20592 \\
\hline 0 & 0 & 0 & 0 & 4926,7 & 0 & 0 & 0 & 0 & 0 & 0 & 1 & 0 & 20592 \\
\hline 0 & 0 & 0 & 0 & 0 & 12426,7 & 0 & 0 & 0 & 0 & 0 & 0 & 1 & 20592 \\
\hline
\end{tabular}

Dessa forma, há duas problemáticas fundamentais: o uso de água está sendo superior ao que é requerido pela cultura, havendo um desperdício de água, ou as áreas estão sendo subutilizadas, não gerando a maior lucratividade ao produtor a partir do que é ofertado.

\section{RESULTADOS E DISCUSSÃO}

Após a modelagem feita, foram obtidas todas as informações para as variáveis básicas da solução do sistema. A solução apresentada pelo SIMPLEX retornou valores correspondentes ao lucro máximo e as variáveis de não negatividade. A Tabela 5 apresenta os resultados encontrados para a função objetivo e para as variáveis de decisão.

De acordo com os valores da Tabela 5, para o produtor rural obter um lucro máximo de $\mathrm{R} \$ 199.091,7$ anual, seria correto realizar o plantio apenas para as culturas de abacaxi (x2) e cana-de-açúcar (x4), cultivando respectivamente 2,074 hectares e 1,926 hectare para as duas culturas em um ano. De acordo com a Tabela 
6, percebe-se que algumas das culturas como milho, feijão e batata doce, utilizados na propriedade não foram plantados, sendo o consumo da água realizado apenas pelo abacaxi e pela cana-de-açúcar. $\mathrm{O}$ abacaxi consumiu totalmente o que fora outorgado, já para a cana-de-açúcar foi necessário o uso de apenas $9.846,83 \mathrm{~m}^{3}$ na irrigação. O cenário otimizado da irrigação possibilita uma economia de $72.881,17 \mathrm{~m}^{3}$ do volume outorgado, representando uma redução de $70,78 \%$ de água.

Tabela 5: Resultados encontrados no modelo.

\begin{tabular}{|l|l|l|l|l|l|}
\hline Função objetivo (R\$) & $199.091,7$ & & & & \\
\hline Variáveis & $\mathrm{x} 1$ & $\mathrm{x} 2$ & $\mathrm{x3}$ & $\mathrm{x} 4$ & $\mathrm{x}$ \\
\hline Quantidade (ha) & 0 & 2,074 & 0 & 1,926 & 0 \\
\hline Lucro total (R\$) & - & $139.935,4555$ & - & $59.141,37$ & - \\
\hline
\end{tabular}

Tabela 6: Restrições de outorga e consumo realizado por cultura.

\begin{tabular}{|l|l|l|}
\hline Restrições & Outorga disponibilizada $\mathbf{( m}^{\mathbf{3}} \mathbf{3}$ & Consumo $\left(\mathbf{m}^{\mathbf{3}} \mathbf{)}\right.$ \\
\hline Milho & 20.592 & 0 \\
\hline Abacaxi & 20.592 & 20.592 \\
\hline Feijão & 20.592 & 0 \\
\hline Cana-de-açúcar & 20.592 & $9.846,83$ \\
\hline Batata doce & 20.592 & 0 \\
\hline Total & 102.960 & $30.078,83$ \\
\hline
\end{tabular}

Financeiramente cada $\mathrm{m}^{3}$ de água custa $0,005 \mathrm{R} \$$, no total, se toda água disponibilizada para a irrigação fosse de fato usada, seriam pagos $514,8 \mathrm{R}$. Caso a outorga fosse realizada de acordo com a quantidade de água utilizada, o valor a ser pago seria então reduzido para 150,39 R\$̦. Visando o detalhamento mais preciso gerou-se o relatório de resposta e de sensibilidade organizados nas tabelas 7 e 8 . 0 objetivo desses relatórios de sensibilidade e de resposta é identificar as alterações que podem ser feitas na estrutura do problema, como: valor máximo e mínimo que os coeficientes da função objetivo e os coeficientes das restrições podem assumir, sem que a programação para a irrigação seja alterada. Além disso, foi possível identificar o valor do acréscimo de uma unidade em uma determinada restrição no valor final da função objetivo.

Tabela 7: Relatório de resposta da otimização.

\begin{tabular}{|c|c|c|c|}
\hline Célula do Objetivo (máx) & & & \\
\hline \multirow[t]{2}{*}{ Função Objetivo } & Valor original & Valor final & \\
\hline & $199.091,733$ & $199.091,733$ & \\
\hline \multicolumn{4}{|l|}{ Células variáveis } \\
\hline Variável & Valor original & Valor final & Número inteiro \\
\hline $\mathrm{X} 1$ & 0 & 0 & Conting. \\
\hline $\mathrm{X} 2$ & 2,074 & 2,074 & Conting. \\
\hline $\mathrm{x} 3$ & 0 & 0 & Conting. \\
\hline $\mathrm{X} 4$ & 1,925 & 1,925 & Conting. \\
\hline $\mathrm{X} 5$ & 0 & 0 & Conting. \\
\hline \multicolumn{4}{|l|}{ Células de restrições } \\
\hline Nome & Valor da Célula & Condição & Status \\
\hline Antes da igualdade & $30.078,826$ & $<=$ & Não-associação \\
\hline Antes da igualdade & 0 & $<=$ & Não-associação \\
\hline Antes da igualdade & 20.592 & $<=$ & Associação \\
\hline Antes da igualdade & $9.486,826$ & $<=$ & Não-associação \\
\hline Antes da igualdade & 4 & $=$ & Associação \\
\hline
\end{tabular}

No relatório de resposta estão exibidos os valores da função objetivo e da quantidade de área que deve ser plantada para cada cultura. Já no relatório de sensibilidade, o intervalo em que o lucro (coeficiente 
de decisão), pode variar sem afetar a solução ótima é entre 36.764,45 e 1.030. Também se obteve o espectro das restrições que são representados no permitido aumentar e reduzir.

Caso seja acrescentado uma unidade em coeficiente de restrição específico, soma-se o valor do preço sombra correspondente na função objetivo, o mesmo ocorre se for subtraído uma unidade num determinado coeficiente de restrição, então diminui-se o respectivo preço sombra na função objetivo. É importante respeitar os limites do que é permitido aumentar e diminuir em cada coeficiente de restrição, sob pena de alterar a solução ótima. Observou-se que, nenhuma das variáveis, exceto a que representa restrição para a cana-de-açúcar que, sofrendo aumento ou redução, possui um valor de sombra de $3,703 \mathrm{~m}^{3}$.

Tabela 8: Relatório de sensibilidade da otimização.

\begin{tabular}{|c|c|c|c|c|c|}
\hline Células Variáveis & & & & & \\
\hline Variável & Final Valor & Reduzido Custo & Objetivo Coeficiente & Permitido aumentar & Permitido reduzir \\
\hline$x 1$ & 0 & $-30.393,1$ & 313,74 & $30.393,1$ & $1 \mathrm{E}+30$ \\
\hline$\times 2$ & 2,074 & 0 & $67.471,29$ & $1 \mathrm{E}+30$ & $36.764,45$ \\
\hline$x 3$ & 0 & $-29.956,6$ & 750,24 & $29.956,6$ & $1 \mathrm{E}+30$ \\
\hline$x 4$ & 1,926 & 0 & $30.706,84$ & $36.764,45$ & $21.098,026$ \\
\hline$\times 5$ & 0 & $-21.098,026$ & $9.608,814$ & $21.098,026$ & $1 \mathrm{E}+30$ \\
\hline \multicolumn{6}{|l|}{ Restrições } \\
\hline Final Valor & Preço sombra & Restrição Lateral R.H. & Permitido aumentar & Permitido reduzir & \\
\hline $30.078,826$ & 0 & 102.960 & $1 \mathrm{E}+30$ & $72.881,173$ & \\
\hline 0 & 0 & 20.592 & $1 \mathrm{E}+30$ & 20.592 & \\
\hline 20.592 & 3,703 & 20.592 & $19.114,8$ & 20.592 & \\
\hline $9.486,826$ & 0 & 20.592 & $1 \mathrm{E}+30$ & $11.105,173$ & \\
\hline 0 & 0 & 20.592 & $1 \mathrm{E}+30$ & 20.592 & \\
\hline 4 & $30.706,84$ & 4 & 2,254 & 1,926 & \\
\hline
\end{tabular}

Com relação a otimização, para que seja feita uma análise mais apurada da melhor situação de plantio para as culturas utilizadas, devem ser acrescentadas mais culturas como variáveis do problema, além de condicionantes como gasto com mão de obra, maquinário e fertilização necessários para realização do plantio. Recomenda-se que seja realizado um estudo mais específico com relação aos custos para produzir cada cultura, tendo em vista que este estudo foi simplificado e não considerou custos relacionados ao transporte, mão-de-obra, fertilizantes, entre outros, já que o foco do trabalho é avaliar o consumo de água atual e o real necessário para a produção. Outro fator que deve ser levado em consideração é a forma de irrigação utilizada na propriedade, pois dependendo do método utilizado, podem ser analisados os melhores usos da área com relação ao aproveitamento de possíveis áreas pouco irrigadas ou feito de forma irregular.

A otimização da irrigação na área de estudo, se realizada considerando a variação dos índices pluviométricos médios trimestrais podem facilitar o melhor uso e ocupação do solo, com sistema de rodizio, possibilitando a melhor solução de plantio de acordo com os diferentes consumos de água e adaptação das culturas às condições climáticas de cada período do ano.

\section{CONCLUSÃO}

A sustentabilidade hídrica requer planejamento e acompanhamento contínuos, com procedimentos de controle de qualidade e quantidade desse recurso. Para obtenção de melhorias na agricultura faz-se necessário o uso e desenvolvimento de metodologias apropriados para cada região, com suas características, acessíveis de serem adotados pelo produtor aumentando a produtividade com o mínimo risco ao meio 
ambiente. O desenvolvimento da agricultura necessita de um melhor planejamento por parte dos órgãos gestores viabilizando a otimização do uso da água, para a melhoria de eficiência de aplicação e ganhos de produtividade sem comprometimento da quantidade e qualidade deste recurso.

A modelagem aplicada mostrou que a solução ótima para o problema é a produção das culturas de abacaxi e cana-de-açúcar para obtenção do maior lucro com menor consumo de água para o produtor em análise. É possível verificar também que o volume de água fornecido pelo órgão regulador muitas vezes é superior ao necessário para irrigação das culturas. Assim, aconselha-se um planejamento/reavaliação do método utilizado para determinar a outorga de água necessária para cada outorgado, utilizando ferramentas computacionais que permitem estimar o consumo real desse recurso.

Recomenda-se que seja realizado um estudo mais específico com relação aos custos para produzir cada cultura, tendo em vista que este estudo foi simplificado. Contudo foi possível observar nesta pesquisa que mudanças precisam ser feitas para maximizar a eficiência dessa prática, cabendo as autoridades competentes aplicarem as soluções propostas, melhorando as fases de planejamento e monitoramento dessa prática de irrigação, maximizando o lucro dos produtores e conservando os recursos hídricos.

\section{REFERÊNCIAS}

AESA. Agência Executiva de Gestão das Águas do Estado da Paraíba. Comunicação pessoal. Campina Grande, 2017

ANA. Agência Nacional de Águas. Conjuntura Recursos Hídricos Brasil. 2017.

CÂMARA JÚNIOR, A. C.. Suporte à decisão para o planejamento agrícola utilizando algoritmos genéticos. Dissertação (Mestrado em Saneamento, Meio Ambiente e Recursos Hídricos) - Universidade Federal de Minas Gerais, Belo Horizonte, 2005.

CONAB. Companhia Nacional de Abastecimento. Acompanhamento da safra brasileira (cana-de-açúcar). SAFRA 2016/17 N.4 - Quarto levantamento. Brasília, 2017.

CONAB. Companhia Nacional de Abastecimento. Acompanhamento da safra brasileira (grãos). SAFRA 2016/17 - N.6 - Sexto levantamento. Brasília, 2017.

CURI, R. C.; CURI, W. F.; ALMEIDA, M. A.. Alternativas de operação de perímetros irrigados com base no uso da água de reservatórios superficiais e subterrâneos. In: CONGRESSO BRASILEIRO DE ÁGUAS SUBTERRÂNEAS, 12. Anais. São Paulo: ABAS, 2002

EMBRAPA. Empresa Brasileira de Pesquisa Agropecuária. Requerimento de água das culturas para fins de dimensionamento e manejo de sistemas de irrigação localizada. Sete Lagoas: EMBRAPA, 2007.

FARIAS, S. R. A.. Operação Integrada dos Reservatórios Engenheiro Ávidos e São Gonçalo. Dissertação (Mestrado em Engenharia de Recursos Hídricos) - Universidade Federa de Campina Grande, Campina Grande, 2004.

LANNA, A. E. L.. Introdução. In: Técnicas quantitativas para o gerenciamento de recursos hídricos. Porto Alegre: UFRGS - ABRH, 1997. p.15-41.

MATEUS, G. R.; LUNA, H. P. C.. Programação não linear. Belo Horizonte: UFMG, 1986.

PERH. Plano Estadual de Recursos Hídricos do Estado da Paraíba. João Pessoa, 2006.

RAGSDALE, C. T.. Modelagem e Análise de Decisão. 6 ed. São Paulo: Cengage Learning, 2009.

RESENDE FILHO, M. A.; ARAÚJO, F. A.; SILVA, A. S.; BARROS, E. S.. Precificação da Água e Eficiência Técnica em Perímetros Irrigados: Uma aplicação da função Insumo Distância Paramétrica. Est. econ., São Paulo, v.41, n.1, p.143-172, 2011.

SANTOS, V. S.. Um modelo de otimização multiobjetivo para análise de sistemas de recursos hídricos. Dissertação (Mestrado) - Universidade Federal de Campina Grande, Campina Grande, 2007.

TUNDISI, J. G.; MATSUMURA-TUNDISI, T.. Recursos hídricos no Século XXI. São Paulo: Oficina de Textos, 2011.

VIEITES, R. G.. Agricultura sustentável: uma alternativa ao modelo convencional. Revista Eletrônica do Programa de Pós-Graduação em Geografia - UFPR, v.5, n.2, p.1-12, 2010.

A CBPC - Companhia Brasileira de Produção Científica (CNPJ: 11.221.422/0001-03) detém os direitos materiais desta publicação. Os direitos referem-se à publicação do trabalho em qualquer parte do mundo, incluindo os direitos às renovações, expansões e disseminações da contribuição, bem como outros direitos subsidiários. Todos os trabalhos publicados eletronicamente poderão posteriormente ser publicados em coletâneas impressas sob coordenação da Sustenere Publishing, da Companhia Brasileira de Produção Científica e seus parceiros autorizados. Os (as) autores (as) preservam os direitos autorais, mas não têm permissão para a publicação da contribuição em outro meio, impresso ou digital, em português ou em tradução. 